\title{
The Expression of CD40 on Monocytes of Children with Primary Humoral Immunodeficiencies
}

\author{
DANUTA KOWALCZYK, ANNA MACURA-BIEGUN, AND MAREK ZEMBALA \\ Department of Clinical Immunology, Institute of Pediatrics, Jagiellonian University Medical College, 30-663 Cracow, Poland
}

\begin{abstract}
The interactions between CD40 and CD40L (CD154) are critical for effective humoral immune response. CD40 signaling facilitates T lymphocyte dependent B cell proliferation and immunoglobulin isotype switch. The objective of our study was to investigate the CD40 and CD40L expression on peripheral blood mononuclear cells (PBMC) of children with symptomatic transient hypogammaglobulinemia (THI), common variable immunodeficiency (CVID) and selective IgA deficiency (SIgAD). Additionally we studied the production of IL-12 and IL-18 by PBMC stimulated with soluble CD40L. CD40 expression was analyzed on B cells and monocytes, CD40L on activated T lymphocytes, using flow cytometry following staining of the cells with appropriate MAb. We found that CD40 expression on B cells and CD40L on activated T cells were essentially similar in the control and patient groups, while the decreased CD40 expression on monocytes was observed in THI and SIgAD patients compared with normal subjects. The most significant decrease of CD40 expression was observed in THI (37\% of positive cells) in comparison with control (81\% of positive cells). IL-12, but not IL-18, release by PBMC was increased in THI and CVID, but not in SIgAD. In conclusion we suggest that the decreased expression of CD40 on monocytes of children with THI and SIgAD, but not CVID, may be involved in the pathomechanism of these immunodeficiencies. (Pediatr Res 59: 816-819, 2006)
\end{abstract}

D espite a rapid progress in understanding the cellular and molecular defects underlying different primary immunodeficiencies, the cause of decreased immunoglobulin production in patients with transient hypogammaglobulinemia of infancy (THI), selective IgA deficiency (SIgAD), and common variable immunodeficiency (CVID) remains elusive. All of these groups of immunodeficiency are characterized by the presence of $\mathrm{B}$ cells in the peripheral blood but defective immunoglobulin production (1).

THI is characterized by delay in $\mathrm{IgG}$, and often $\operatorname{IgA}$, synthesis for as long as 40 mo of age, which spontaneously return to normal values at the age of 2-4 y (1). Affected children often suffer from recurrent otitis, upper respiratory tract infections, food intolerance and atopy. According to Walker et al. (2), THI appears to have a similar prevalence to

Received September 21, 2005; accepted January 18, 2006.

Correspondence: Danuta Kowalczyk, M.D., Ph.D., Jagiellonian University Medical College, Institute of Paediatrics, Department of Clinical Immunology, Wielicka str. 265, Cracow, Poland, tel.: (++48 12) 658-24-86; fax.: (++48 12) 658-17-56; e-mail: dkowalcz@cm-uj.krakow.pl

This work was supported by the State Research Committee (grant no 3 PO5E O39 23)

DOI: 10.1203/01.pdr.0000219298.96471.18 symptomatic $\mathrm{SIg} \mathrm{AD}$, the reasons for delayed immunoglobulin synthesis in THI remain unknown (2).

SIgAD is the most common primary immunodeficiency. Approximately $60 \%$ of subjects with IgA deficiency are asymptomatic. Those with symptoms suffer from recurrent infections of respiratory tract, gastrointestinal disorders, allergy and autoimmune diseases (3). The term CVID is used to describe an incompletely defined syndrome characterized by defective antibody formation, usually accompanied by decreased serum $\operatorname{IgG}$ and $\operatorname{IgA}$ levels and generally, but not invariably, decreased serum IgM level (1). First symptoms may occur at any time of life, but the most common disease onset is between 1-5 and 16-25 y of life (4).

Many studies attempting to identify the immunologic defects in CVID have been published. Recently identified monogenic defects (ICOS, TACI, BAFF-R and CD19 defects) account for about $10 \%$ of cases, but the immunopathogenesis of the majority of CVID cases still remains unexplored $(5,6)$. The variable clinical features and variety of affected immunologic functions suggest involvement of multiple pathogenetic factors.

The production of antibodies is regulated by a complex array of cellular and molecular interactions that take place between antigens and cells of the innate and adaptive immune system. One of the most important interactions for antibody production is the engagement of CD40 by its ligand CD154 $(7,8)$. CD40 molecule is a transmembrane receptor which belongs to TNF receptor superfamily and is expressed on B cells, monocytes and dendritic cells. It is involved in the regulation of humoral immunity and cytokine production (7). Cross-linking of CD40 on B cells by its ligand (CD40L) present on activated $\mathrm{T}$ cells triggers $\mathrm{B}$ cells proliferation, prevents $\mathrm{B}$ cells apoptosis and in conjunction with interleukins, induces a switch toward $\mathrm{IgG}$ and IgA production (9). The role of CD40-CD40L interaction in the cooperation between $\mathrm{T}$ cells and macrophages has also been clearly demonstrated (10). Ligation of CD40 on macrophages triggers production of different cytokines, including IL12 , and enhances their $\mathrm{T}$ cell stimulatory activity (11).

Abbreviations: APCs, antigen presenting cells; BAFF-R, B-cell activating factor of the tumor necrosis factory family-receptor; CVID, common variable immunodeficiency; ICOS, inducible co-stimulator of activated T cells; mAbs, monoclonal antibodies; PBMC, peripheral blood mononuclear cells; sCD40L, soluble CD40 ligand; SIgAD, selective IgA deficiency; TACI, transmembrane activator and calcium modulator and cyclophillin ligand interactor; THI, transient hypogammaglobulinemia of infancy 
The main purpose of this study was the determination of changes in the expression of CD40 on B cells and monocytes and CD40L on activated T cells in children with THI, CVID and SIgAD, whose circulating peripheral blood mononuclear cells (PBMC) have previously been shown to produce high levels of TNF $\alpha$, TNF $\beta$ and IL-12 (12-14).

\section{METHODS}

Patients. There were 27 children with THI (total serum IgG level $<2$ SD of normal values for age measured at least two times within three months time period, normal or decreased level of IgA and normal IgM level)—21 boys and 6 girls, mean age $1.9 \pm 0.9 \mathrm{y}$. We previously suggested that in the essence THI is characterized by a low serum IgG, the ability to produce antibodies following immunizations and recovery of normal IgG levels when follow-up is sufficient (13). All children in this cohort were later found to reach normal IgG levels. The SIgAD group (IgA serum level below $0.05 \mathrm{~g} / \mathrm{L}$, normal levels of IgG and $\operatorname{IgM}$ ) consisted of 36 children ( 23 boys and 13 girls, mean age 6.3 $\pm 3.6 \mathrm{y})$.

The group of patients with CVID consisted of 21 patients ( 15 boys and 6 girls, mean age $5.6 \pm 3.5 \mathrm{y}$ ). The diagnosis of CVID was established upon the criteria of IUIS Scientific Committee (1). Control group was formed from children with recurrent infections in whom immunodeficiency was excluded ( 12 boys and 7 girls with mean age $2.9 \pm 1.8 \mathrm{y}$ ).

Presented patients were selected from children referred to our outpatient department with recurrent or chronic infections. Samples of blood were taken during routine diagnostic procedures. Informed consent was obtained from the parents. The study was approved by the Ethical Committee of the Jagiellonian University.

$\mathrm{IgA}, \mathrm{IgG}, \mathrm{IgM}$ levels in patients sera were determined using laser nephelometer (Behring Nephelometer 100, Behringwerke AG, Germany). The number of circulating CD3, CD4, CD8, CD19, T $\alpha \beta$ and $\mathrm{T} \gamma \delta$ lymphocytes, CD3/HLA-DR and NK cells were assessed by flow cytometry following staining with appropriate MAb (mAbs). Lymphocyte function assessed by proliferative response of PBMC to mitogens: phytohemagluttinin (PHA), pokeweed mitogen (PWM) and anti-CD3 MAb was also tested. After $72 \mathrm{~h}$ of incubation PBMC with mitogens $\left[{ }^{3} \mathrm{H}\right]$ thymidyne was added. Cells were harvested after $16 \mathrm{~h}$, and incorporated radioactivity was determined on a scintillation $\beta$-counter. All these parameters were within normal range in THI and SIgAD. In CVID group various abnormalities were observed (decreased levels of $\mathrm{CD}^{+}$cells and $\mathrm{CD} 19^{+}$cells, decreased proliferative response to mitogens and/or anti-CD3 MAb).

Antibodies and reagents. Rabbit anti-human IgG, IgA, IgM (Dade Behring, Marburg, Germany) were used to quantify IgG, IgA and IgM level in the sera. To determine the $\mathrm{B}, \mathrm{T}$ cells and their subsets the following fluorescein isothiocynate (FITC) or phycoerythrin (PE)-conjugated, the following mAbs or their pairs were used: anti-CD3/CD19, anti-CD4/CD8, anti-CD3/HLA-DR, anti-TCR $\alpha \beta$ (FITC), anti-TCR $\gamma \delta$ (Becton Dickinson Heidelberg, Germany). Anti-CD40 FITC, anti-CD40 ligand (CD154)-PE, anti-CD19-PE, antiCD14-PE and relevant isotype controls were purchased from BD PharMingen (San Diego, CA).

Determination of CD40 and CD40L expression on PBMC. PBMCs were isolated from heparinized peripheral blood by standard Isopaque/Ficoll (Pharmacia, Uppsala, Sweden) density gradient centrifugation. CD40 expression on $\mathrm{B}$ cells and monocytes was studied by the double staining technique using the following pairs of mAbs: anti-CD40 FITC/CD19 PE or anti-CD40 FITC/ CD14 PE or relevant isotype controls. To determine the expression of CD40L on $\mathrm{T}$ cells, PBMC were activated with phorbol myristate acetate (PMA) $(50 \mathrm{ng} / \mathrm{mL}$, Sigma Chemical Co., St. Louis, MO) plus ionomycin (300 $\mu \mathrm{g} / \mathrm{mL}$, Sigma Chemical Co.) for 4-6 h, then washed and double stained using anti-CD3 FITC/CD154 PE mAbs or relevant isotype controls. Samples were analyzed in FACSCalibur flow cytometer (Becton Dickinson, Palo Alto, CA).

Determination of $\boldsymbol{I L}-12$ and $\boldsymbol{I L}-18$ production. Isolated PBMC $(1 \times$ $10^{6} / \mathrm{mL}$ ) were suspended in RPMI 1640 medium with $10 \%$ FCS (Biochrom, Berlin, Germany) and cultured in the presence of recombinant interferon gamma (IFN $\gamma)(10 \mathrm{ng} / \mathrm{mL}$, Sigma Chemical Co.), and soluble form of CD40L/TRAP (sCD40L, $1.0 \mu \mathrm{g} / \mathrm{mL}$, Pepro Tech EC LTD, London, UK) for $24 \mathrm{~h}$ at $37^{\circ} \mathrm{C}$ in $5 \% \mathrm{CO}_{2}$. Supernatants were harvested and kept at $-70^{\circ} \mathrm{C}$ until testing. IL-12 (p40/p70) production was determined using commercially available matched antibody pair for ELISA (antihuman IL-12 (p40/p70) and biotinylated antihuman IL-12 (p40/p70) and recombinant human IL-12 protein as the standard (Pharmingen) according to manufacturer's protocol (level of detection $-20 \mathrm{pg} / \mathrm{mL}$ ). IL-18 level was measured by human IL-18 ELISA kit (MBL, Naka-ku Nagoya, Japan, level of detection $-12.5 \mathrm{pg} / \mathrm{mL}$ ).

Statistical analysis. The Mann-Whitney two-tailed test was used. The difference was regarded as significant when $\mathrm{p}$ value was $<0.05$.

\section{RESULTS}

CD40 expression on B cells and monocytes. There were no differences in CD40 expression on B cells. In all tested groups of patients as well as in control group CD40 were expressed on more than $90 \%$ of $\mathrm{CD} 19^{+}$cells (observed values were from 93.9 to $100.0 \%)$. In contrast, the decreased proportion of $\mathrm{CD} 40^{+}$monocytes was observed in all studied groups of patients with hypogammaglobulinemia (Fig. 1). The lowest number of $\mathrm{CD} 40^{+}$monocytes was observed in THI group (mean $37.2 \% \pm 29.5 \%$ ), that was significantly decreased compared with the control group (mean $81.7 \% \pm 15.9 \%, p<$ $0.0001)$, CVID group $(p<0,0013)$ and $\operatorname{SIgAD}(p<0.0115)$. In group of patients with SIgAD mean percentage of monocytes with CD40 expression was also significantly lower $(58.3 \pm 30.0 \%)$ than in the control group $(p<0.0072)$. In patients with CVID the proportion of CD40 ${ }^{+}$monocytes was not significantly different (mean $71.9 \pm 31.6 \%$ ) from the control group. The level of CD40 expression measured as mean fluorescence intensity was also examined and no significant differences have been detected between control and patient groups. However in patients with THI and SIgAD in addition to decreased number of monocytes presenting CD40 on their surface, also the level of CD40 expression (measured as mean intensity of fluorescence intensity) was significantly decreased compared with CVID group (data not shown).

CD40L expression on activated T cells. The expression of CD40L on activated T lymphocytes in THI and SIgAD patients was comparable to the control group (Fig. 2). In CVID

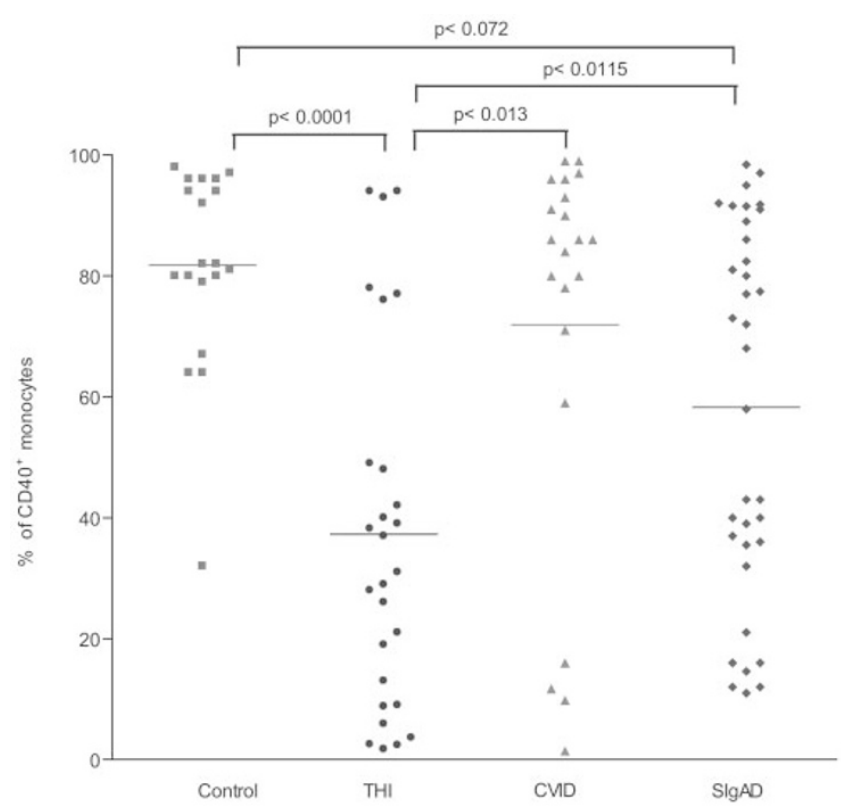

Figure 1. CD40 expression on monocytes in patients with THI, CVID, SIgAD and control subjects. Isolated PBMC were double labelled with: anti-CD40 FITC/CD14 PE mAbs or relevant isotype controls. Samples were analyzed by flow cytometry. Results show the percentage of CD40 positive monocytes $\left(\mathrm{CD} 14^{+}\right.$cells). 


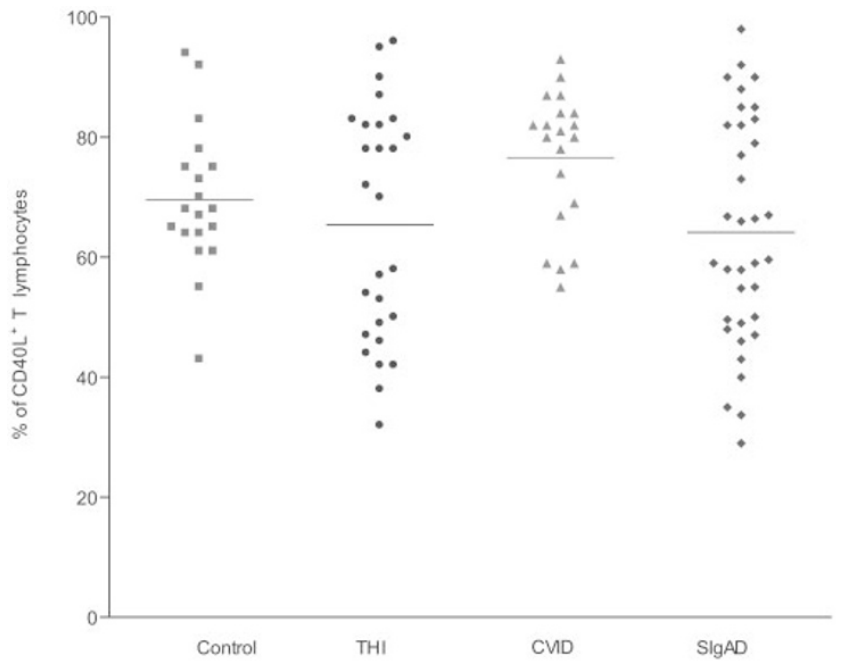

Figure 2. The expression of CD40L on activated T lymphocytes in patients with THI, CVID, SIgAD and the control group. PBMC were stimulated with PMA plus ionomycin for 4-6 h, washed, then double stained with: anti-CD3 FITC/CD154 PE mAbs and analyzed by flow cytometry. Results are expressed as the percentage of $\mathrm{CD} 40 \mathrm{~L}$ positive $\mathrm{T}$ lymphocytes $\left(\mathrm{CD}^{+}{ }^{+}\right.$cells).

patients the expression of CD40L was slightly increased but differences were not significant.

$I L-12$ and $I L-18$ production. As previous studies shown that cross linking of CD40 with CD40L as a single signal is insufficient to induce IL-12 production and that IFN $\gamma$ can act as a co-stimulatory factor, PBMC were stimulated with IFN $\gamma$ and sCD40L $(1 \mu \mathrm{g} / \mathrm{mL})(15,16)$ Detectable levels of IL-12 were observed in $42 \%$ of patients with THI, $50 \%$ of CVID, $37 \%$ of SIgAD and in $18 \%$ of control subjects. Compared with the control group (mean IL-12 production $376 \pm 265 \mathrm{pg} / \mathrm{mL}$ ) the highest level of IL-12 in the culture supernatants was observed in THI patients $(1085 \pm 1025 \mathrm{pg} / \mathrm{mL})$. Also in CVID patients IL-12 production was increased $(592 \pm 350 \mathrm{pg} / \mathrm{mL})$ compared with the control group, while in SIgAD it was comparable to that in the control group ( $363 \pm 353 \mathrm{pg} / \mathrm{mL}$ ). These differences were not significant. In contrast, IL-18 production in patients with hypogammaglobulinemias was not altered (mean IL-18 levels were as follows: $17.0 \pm 19 \mathrm{pg} / \mathrm{mL}$ in control group, $13.0 \pm 18$ in THI, $6.8 \pm 3.4 \mathrm{pg} / \mathrm{mL}$ in CVID and $8.6 \pm 11 \mathrm{pg} / \mathrm{mL}$ in SIgAD group).

\section{DISCUSSION}

The mechanisms responsible for hypogammaglobulinemia in primary humoral immunodeficiencies with the presence of circulating B cells (e.g., THI, CVID, SIgAD) has not been clearly established. It is likely that no single abnormality, but rather several different factors may be responsible for decreased immunoglobulin synthesis. Numerous studies have demonstrated that interactions between CD40 and CD40L are crucial for B cell isotype switching, germinal center formation, memory $\mathrm{B}$ cell generation, and the long-term production of antibodies $(7,8,17)$. Furthermore, CD40 expression on nonB cells antigen presenting cells (APCs) is necessary for $\mathrm{CD}^{+} \mathrm{T}$ cells to acquire a follicular homing phenotype, suggesting that insufficient or inappropriate $\mathrm{T}$ cell priming may be responsible for the poor humoral response (17).
In the current study we investigated the expression of CD40 on B cells and monocytes, and CD40L expression on activated $\mathrm{T}$ cells in children with THI, CVID and SIgAD.

The main finding of this study was significantly decreased CD40 expression on monocytes in children with THI and SIgAD, while the CD40L expression on activated T cells in those groups were comparable to control. In CVID patients the expression of CD40 on monocytes was not significantly decreased, whereas CD40L expression on activated T cells was either unchanged or slightly increased.

The inability of activated $\mathrm{T}$ cells to express a functionally normal CD40L was described in X-linked hyper-IgM syndrome, characterized by a lack of isotype switching (18). Decreased CD40L expression was observed in patients with tuberculosis (19), that correlated with decreased antigenstimulated IFN $\gamma$ production by PBMC of these patients. Increased or unaltered CD40L expression on T lymphocytes in CVID patients demonstrated in study is in contrast to other data demonstrating decreased CD40L expression on $\mathrm{T}$ lymphocytes in CVID patients (20-22). However, patients studied by Oliva and Brugnoni were mainly adults (mean age 40.5 and 13.5) while mean age of our patients was $5.6 \mathrm{y}$.

On the other hand, an increased CD40L expression was observed in autoimmune diseases such as Grave's disease, rheumatoid arthritis, and in inflammatory bowel disease (23). Autoimmune diseases and endocrinopathies, particularly involving thyroid, frequently occur in patients with CVID (24), that may be related to the overexpression of CD40L in some of our patients.

Little is known about changes in CD40 expression on human monocytes in disease states. Recent studies in mouse model showed that CD40 expression on nonB cells APCs is necessary for $\mathrm{CD}^{+} \mathrm{T}$ cells to acquire a follicular homing phenotype. Filatreau et al. (25) have shown that insufficient T cell priming may be responsible for a poor humoral immune response in $\mathrm{CD}^{40-/-}$ mice. In chimeric mice selective absence of CD40 on B cells had no effect on follicular migration of $\mathrm{T}$ cells when CD40 was present on APCs. T cell activation in those chimeric mice was also unimpaired. T cells are required in the follicles to provide help for development of high affinity antibodies and memory B cells (26), hence impaired CD40 expression on APCs (e.g., monocytes) may result in impaired migration of $\mathrm{T}$ cells and in consequence alteration in providing help to B cells for effective antibody production. Therefore, decreased expression of CD40 on nonB cells may be one of the factors responsible for insufficient humoral immune response in patients with THI. It is an open question whether decreased CD40 on monocytes in THI may be linked to similar observations concerning lung macrophages in patients with atopy, which is frequently observed in symptomatic THI (27).

There is evidence that CD40 ligation triggers APCs activation and IL-12 production (8). Our data showing the decreased expression of CD40 on monocytes in THI patients led to a question whether and how does it alter the cytokine production by PBMC. IL-12 and IL-18 were chosen because among PBMC, monocytes are the main producers of these cytokines (28). For that purpose PBMC were stimulated with IFN $\gamma$ and 
cultured in the presence of sCD40L, then IL-12 and IL-18 levels were measured in the culture supernatant. Results showed that IL-12 release was increased in all groups of patients, and the highest levels were observed in THI.

IL-18 levels were not altered. These results are in keeping with our previous observations on an enhanced intracellular IL-12 production in these hypogammaglobulinaemias (14), and suggest that sCD40L does not significantly modify IFN $\gamma$-driven cytokine release. In our hands sCD40L alone did not stimulate significant release of IL-12. This is in accordance with findings of Yamauchi et al. (29), who demonstrated in the mouse model that IL-12 production may be independent of CD40 ligation. Data provided by Han et al. (30) show that CD40-CD40L receptor interactions have a lesser role in T-dependent activation of human monocytes, this pair is active if monocytes are primed by IFN $\gamma$, that is in accordance with our findigs.

To our knowledge the present data are the first demonstration of an abnormal expression of CD40 on monocytes in some types of hypogammaglobulinemia with normal level of circulating B cells, in particular THI, that may be involved in their pathomechanism.

Significantly decreased expression of CD40 in symptomatic THI in comparison to CVID may be regarded as an early marker differentiating these two diseases, both occurring in early childhood, but with different severity and long term prognosis.

Acknowledgments. The authors thank Ms Mariola Hyszko, Ms Barbara Hajto, Ms Karolina Bukowska and Ms Małgorzata Gawlicka for their skillful technical assistance.

\section{REFERENCES}

1. 1999 Primary immunodeficiency diseases. Report of an IUIS Scientific Committee. International Union of Immunological Societies. Clin Exp Immunol 118 (Suppl. 1): $1-28$

2. Walker AM, Kemp AS, Hill DJ, Shelton MJ 1994 Features of transient hypogammaglobulinemia in infants screened for immunological abnormalities. Arch Dis Child; 70:183-186

3. Plebani A, Ugazio AG, Monafo V, Burgio GR 1986 Clinical heterogeneity and reversibility of selective immunoglobulin A deficiency in 80 children. Lancet $1: 829-831$

4. Hammarstrom L, Vorechovsky I, Webster D 2000 Selective IgA deficiency (SIgAD) and common variable immunodeficiency (CVID). Clin Exp Immunol 120:225-231

5. Cambronero R, Sewell WA, North ME, Webster AD, Farrant J 2000 Up-regulation of IL-12 in monocytes: a fundamental defect in common variable immunodeficiency. J Immunol 164:488-494

6. Goldacker S, Warnatz K 2005 Tackling the heterogeneity of CVID. Curr Opin Allergy Clin Immunol 5:504-509

7. Van Kooten C, Banchereau J 2000 CD40-CD40 ligand. J Leukoc Biol 67:2-17

8. Foy TM, Aruffo A, Bajorath J, Buhlmann JE, Noelle RJ 1996 Immune regulation by CD40 and its ligand GP39. Annu Rev Immunol 14:591-617
9. Revy P, Geissmann F, Debre M, Fischer A, Durandy A 1998 Normal CD40mediated activation of monocytes and dendritic cells from patients with hyper-IgM syndrome due to a CD40 pathway defect in B cells. Eur J Immunol 28:3648-3654

10. Kiener PA, Moran-Davies P, Rankin BM, Wahl AF, Aruffo A, Hollenbaugh D 1995 Stimulation of CD40 with purified soluble gp39 induces proinflammatory responses in human monocytes. J Immunol 155:4917-4925

11. Cella M, Scheidegger D, Palmer-Lehmann K, Lane P, Lanzavecchia A, Alber G 1996 Ligation of CD40 on dendritic cells triggers production of high levels of interleukin-12 and enhances T cell stimulatory capacity: T-T help via APC activation. J Exp Med 184:747-752

12. Kowalczyk D, Pietrzyk JJ, Zembala M 1994 TNF production in children with humoral immunodeficiency. Acta Paediatr 83:1310-1311

13. Kowalczyk D, Mytar B, Zembala M 1997 Cytokine production in transient hypogammaglobulinemia and isolated IgA deficiency. J Allergy Clin Immunol 100:556562

14. Kowalczyk D, Baran J, Webster AD, Zembala M 2002 Intracellular cytokine production by Th1/Th2 lymphocytes and monocytes of children with symptomatic transient hypogammaglobulinemia of infancy (THI) and selective IgA deficiency (SIgAD). Clin Exp. Immunol 127:507-512

15. Snijders A, Kalinski P, Hilkens CM, Kapsenberg ML 1998 High-level IL-12 production by human dendritic cells requires two signals. Int Immunol 10:15931598

16. Allakhverdi Z, Bouguermouh S, Rubio M, Delespesse G 2005 Adjuvant activity of pollen grains. Allergy 60:1157-1164

17. Lee BO, Moyron-Quiroz J, Rangel-Moreno J, Kusser KL, Hartson L, Sprague F, Lund FE, Randall TD 2003 CD40, but not CD154, expression on B cells is necessary for optimal primary B cell responses. J Immunol 171:5708-5717

18. Kroczek RA, Graf D, Brugnoni D, Giliani S, Korthuer U, Ugazio A, Senger G, Mages HW, Villa A, Notarangelo LD 1994 Defective expression of CD40 ligand on $\mathrm{T}$ cells causes "X-linked immunodeficiency with hyper-IgM (HIGM1)". Immunol Rev 138:39-59

19. Samten B, Thomas EK, Gong J, Barnes PF 2000 Depressed CD40 ligand expression contributes to reduced gamma interferon production in human tuberculosis. Infect Immun 68:3002-3006

20. Oliva A, Scala E, Quinti I, Paganelli R, Ansotegui IJ, Giovanetti A, Pierdominici M, Aiuti F, Pandolfi F 1997 IL-10 production and CD40L expression in patients with common variable immunodeficiency. Scand J Immunol 46:86-90

21. Farrington M, Grosmaire LS, Nonoyama S, Fischer SH, Hollenbaugh D, Ledbetter JA, Noelle RJ, Aruffo A, Ochs HD 1994 CD40 ligand expression is defective in a subset of patients with common variable immunodeficiency. Proc Natl Acad Sci 91:1099-1103

22. Brugnoni D, Airo P, Lebovitz M, Malacarne F, Ugazio AG, Notarangelo LD, Plebani A, Cattaneo R 1996 CD4+ cells from patients with Common Variable Immunodeficiency have a reduced ability of CD40 ligand membrane expression after in vitro stimulation. Pediatr Allergy Immunol 7:176-179

23. Liu Z, Colpaert S, D'Haens GR, Kasran A, de Boer M, Rutgeerts P, Geboes K, Ceuppens JL 1999 Hyperexpression of CD40 ligand (CD154) in inflammatory bowel disease and its contribution to pathogenic cytokine production. J Immunol 163:4049-4057

24. Ballow M 2002 Primary immunodeficiency disorders: antibody deficiency. J Allergy Clin Immunol 109:581-591

25. Fillatreau S, Gray D 2003 T cell accumulation in B cells follicles is regulated by dendritic cells and is independent of B cell activation. J Exp Med 197:195-206

26. MacLennan IC, Gulbranson-Judge A, Toellner KM, Casamayor-Palleja M, Chan E, Sze DM, Luther SA, Orbea HA 1997 The changing preference of T and B cells for partners as T-dependent antibody responses develop. Immunol Rev 156:53-66

27. Tang C, Ward C, Reid D, Bish R, O'Byrne PM, Walters EH 2001 Normally suppressing CD40 coregulatory signals delivered by airway macrophages to $\mathrm{T}_{\mathrm{H}} 2$ lymphocytes are defective in patients with atopic asthma. J Allergy Clin Immunol 107:863-870

28. Maruo S, Oh-hora M, Ahn HJ, Ono S, Wysocka M, Kaneko Y, Yagita H, Okumura K, Kikutani H, Kishimoto T, Kobayashi M, Hamaoka T, Trinchieri G, Fujiwara H 1997 B cells regulate CD40 ligand-induced IL-12 production in antigen-presenting cells (APC) during T cell/APC interactions. J Immunol 158:120-126

29. Yamauchi PS, Bleharski JR, Uyemura K, Kim J, Sieling PA, Miller A, Brightbill H, Schlienger K, Rea TH, Modlin RL 2000 A role for CD40-CD40 ligand interactions in the generation of type 1 cytokine responses in human leprosy. J Immunol 164:1506-1512

30. Han P, McDonald T, Hodge G 2004 Potential immaturity of the T-cell and antigen-presenting cell interaction in cord blood with particular emphasis on the CD40-CD40 ligand costimulatory pathway. Immunology 113:26-34 